\title{
O PDI como Referente para Avaliação de Instituições de Educação Superior: Lições de uma Experiência
}

Stella Cecília Duarte Segenreich

\section{RESUMO}

Sistema Nacional de Avaliação da Educação Superior (SINAES), instituído em abril de 2004, colocou o Plano de Desenvolvimento Institucional (PDI) como um de seus principais eixos de referência. Neste trabalho será descrita e analisada a experiência de organização do PDI em uma universidade consolidada do Rio de Janeiro, em 2002, com o objetivo de demonstrar que, à medida em que este plano é resultado de uma construção coletiva, impõe-se, naturalmente como fio condutor para qualquer avaliação, interna ou externa. Inicialmente, é feita uma análise da concepção governamental do PDI naquele momento para, em seguida, descrever a experiência realizada. Finalmente são levantadas questões e alternativas de ação como, por exemplo, a necessidade de inserir a avaliação de cada PDI, no bojo do projeto de avaliação interna do SINA$E S$, não só em relação às metas nele propostas mas, também, em relação ao seu próprio processo de construção e implementação.

Palavras-chave: Educação superior. Avaliação institucional. Plano de desenvolvimento institucional. Políticas institucionais. Planejamento. SINAES. PDI. Universidade.

ABSTRACT

The Plan of Institutional Development as reference to assess higher education institutions: lessons from experience

The National System to Assess Superior Education (SINAES), created in April 2004 placed the Institutional Development Plan (PDI) as one if its main reference axle.

This report will describe and review the

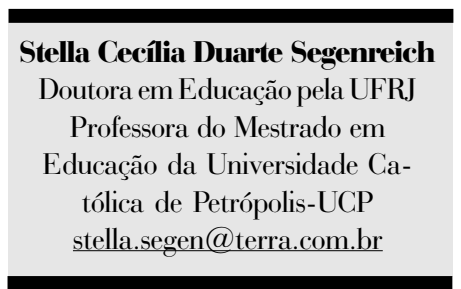

Stella Cecília Duarte Segenreich experience obtained from the organization of PDI in a Rio de Janeiro consolidated university in 2002 with the objective of showing that, as long as this plan is the result of a collective construction, it naturally positions itself as the leading device for any assessment, either internally or externally. Initially, the governmental conception of PDI in that moment is analyzed and the experience achieved is described. Finally, issues and alternatives of action are brought up, as for instance, the necessity of inserting the assessment of 
each PDI within the project of internal assessment of SINAES, not only in relation to the targets proposed but also in what concerns its own process of construction and implementation.

Keywords: Superior education. Institutional assessment. Plan of Institutional Development. Institutional policies. Institutional planning. SINAES. PDI. Institutions of superior teaching. Self-assessment.

\section{RESUMEN}

\section{El Plan de Desarrollo} Institucional como referente para evaluación de instituciones de educación superior: lecciones de una experiencia

El Sistema Nacional de Evaluación de la Educación Superior (HADOS), constituido en abril de 2004, puso el Plan de Desarrollo Institucional (PDI) como uno de sus principales ejes de referencia. En este trabajo será descrita y analizada la experiencia de organización del PDI en una universidad consolidada de Río de Janeiro, en 2002, con el objetivo de demostrar que, como este plan es resultado de una construcción colectiva, se impone, naturalmente como hilo conductor para cualquier evaluación, interna o externa. Inicialmente, se hace un análisis de la concepción gubernamental del PDI en aquel momento para, enseguida, describir la experiencia realizada. Al fin se levantan las cuestiones y alternativas de acción como, por poner un ejemplo, la necesidad de inserir la evaluación de cada PDI, en el diseño del proyecto de evaluación interna del HADOS, no solo con relación a las metas en él propuestas sino, también, con relación a su propio proceso de construcción e implementación.

Palabras-clave: Educación Superior. Evaluación Institucional. Plan de Desarrollo Institucional. Políticas institucionales. Planificación institucional. HADOS. PDI. Instituciones de enseñanza superior. Auto-evaluación.

\section{INTRODUÇÃO}

As políticas públicas e os debates acadêmicos, em torno da avaliação na educação superior, têm-se concentrado em torno, principalmente, nas diferentes concepções de avaliação e de universidade que expressam. Educadores que vêm trabalhando esta questão (DIAS SOBRINHO, 1995; RISTOFF, 1995; SGUISSARDI, 1997; AFONSO, 2000; BELLONI et al., 2003), no Brasil e no exterior, estabelecem uma contraposição entre uma tendência meritocrática/de regulação/ de controle, atribuída ao Estado, e uma concepção de avaliação institucional formativa/voltada para a transformação/ acadêmico-crítica, defendida por representantes da comunidade acadêmica das universidades.

A instituição do Sistema Nacional de Avaliação da Educação Superior - SINAES, em abril de 2004 ( BRASIL, 2004), é fruto de intenso trabalho da Comissão Especial de Avaliação da Educação Superior - CEA, presidida pelo professor José Dias Sobrinho (um dos autores que defendem a avaliação formativa), justamente no propósito de articular regulação e avaliação educativa. Esse grupo de educadores, nomeado em abril de 2003 pelo então Ministro da Educação Cristovam Buarque, contextualiza seu trabalho numa visão abrangente dos processos avaliativos sem dissociar estes da necessária regulação do Estado para fomentar e supervisionar o sistema em seu 
conjunto, mas também reconhece a importância de uma política capaz de refundar a missão pública do sistema de educação brasileiro, respeitando sua diversidade, mas tornando-o compatível com as exigências de qualidade, relevância social e autonomia. (COMISSÃO ESPECIAL DE AVALIAÇÃO DAEDUCAÇÃO SUPERIOR, 2004, p. 13).

Ao longo dos quatro meses seguintes a CEA se reuniu em Brasília e em vários pontos do país assim como desenvolveu um amplo processo de interlocução com a sociedade para chegar a uma proposta encaminhada ao MEC, servindo de base ao texto da Lei $n^{\circ} 10.861$ que instituiu o SINAES.

Não é objetivo deste trabalho analisar tal sistema, mas destacar a importância do Plano de Desenvolvimento Institucional, geralmente conhecido como PDI, no quadro de nossa realidade. No artigo terceiro, da referida Lei, enuncia-se como primeira dimensão a ser objeto de avaliação precisamente "a missão e o plano de desenvolvimento institucional" (BRASIL, 2004). Mais do que isso, endossando Sguissardi (1997), consideramos que o PDI deve tornar-se referência básica para o estabelecimento de qualquer critério ou processo de avaliação. $\bigcirc$ foco deste trabalho centra-se na descrição de uma experiência concreta de desenvolvimento participativo do PDI com o objetivo de demonstrar que, à medida que resulta de uma construção coletiva, impõe-se, naturalmente, como o fio condutor para qualquer processo de avaliação, interna ou externa. Uma análise da trajetória de construção de cada PDI se revela imprescindível no processo de avaliação institucional que as instituições de educação superior estão iniciando no contexto do SINAES, principalmente tendo em vista que nem sempre se verifica ter sido o PDI fruto da referida construção. Em vez de se tornar um fio condutor do processo de avaliação, ele pode vir a se constituir um fardo incômodo para essas instituições se não for, também, objeto de avaliação.

O reconhecimento dessa base referencial do PDI para a avaliação institucional faz parte do próprio conceito de avaliação adotado no documento em análise. Partiu-se da definição de avaliação como um ato pelo qual se formula um juízo de valor sobre um objeto (indivíduo, ação, projeto, etc.), por meio de um confronto entre a realidade observada desse objeto e um modelo ideal que nos serve como referência (HADJI, 1994, 1997). Importa observar que o modelo ideal (no caso, o PDI) do que deve ser esse objeto antecede a avaliação porque não se pode apreciar um objeto sem uma idéia clara de sua natureza. Esse modelo ideal, definido como "referente" por Hadii, pode ser traduzido, num processo de avaliação institucional, em termos de finalidades, metas e planos a médio e curto prazo. Um plano de desenvolvimento institucional, nessa perspectiva, poderia espelhar a tradução, em médio prazo, das propostas de uma instituição de ensino superior no sentido de consolidar sua trajetória.

Neste trabalho, será descrita e analisada a experiência de organização do PDI em uma universidade consolidada do Rio de Janeiro. Inicialmente, faz-se uma análise da concepção governamental de plano de desenvolvimento que permeava o PDI e sua relação com o processo de avaliação, naquele momento específico. Em seguida, a proposta e a metodologia de construção do referido plano, na experiência objeto de estudo, é descrita em suas diferentes etapas para, finalmente, se proceder a uma análise das possibilidades e dificuldades de se estabelecer o PDI nos moldes descritos e como "referente" da proposta de avaliação do SINAES. 


\section{O PDI como Proposta Governamental}

O PDI tem suas raízes em duas atribuições definidas pela LDB que são de competência do MEC: credenciamento e avaliação institucional (BRASIL, 1996). Como em vários outros aspectos, a LDB enunciou estas atribuições, deixando seu detalhamento operacional para regulamentação posterior.

Entretanto, essa regulamentação somente viria, de forma mais clara, cinco anos depois, através do Decreto 3860 de 9 de julho de 2001 ( BRASIL, 2001), que introduziu de modo terminante a figura do PDI como : um dos elementos do processo de credenciamento de IES - Centros Universitários (art. 11) e Institutos Superiores de Educação (art. 14) - sem mencionar explicitamente as universidades; ou como um dos 11 itens a serem considerados na avaliação institucional das IES (art. 17), incluindo as universidades.

Aprovado em dezembro desse mesmo ano, o Parecer CNE/CES 1366/2001 (CONSELHO NACIONAL DE EDUCAÇÃO, 2001, p. 3) destaca a importância do PDI como manifestação específica e "livre" da instituição, nos seguintes termos: "[...] reforça-se no presente parecer a importância e a relevância do plano de desenvolvimento institucional, que determina a missão de cada instituição e as estratégias que as mesmas livremente elegem para atingir metas e objetivos".

Todavia, a Resolução 10/2002 (CONSELHO NACIONAL DE EDUCAÇÃO, 2002), aprovada em março do ano seguinte, significa uma reviravolta em relação à posição do PDI, como avaliação institucional, frente ao MEC: de uma dimensão de avaliação entre 11 indicadas no Decreto 3860/2001 (BRASIL, 2001), passa a englobar a sua maioria.
No artigo 7, é afirmado que "o Plano de Desenvolvimento Institucional, que se constitui em compromisso da instituição com o MEC, é requisito aos [para os] atos de credenciamento e recredenciamento de instituições de ensino superior e poderá ser exigido também no âmbito das ações de supervisão realizadas pelo SESu/MEC" (BRASIL, 2001, p. 3). Comparando-se este artigo com a citação do parecer, de onde se originou a resolução, percebe-se a diferença de discurso.

Em junho de 2002, o MEC, através do Sistema de Acompanhamento de Processos das Instituições de Ensino Superior ( SAPIEnS/MEC), publica documento destinado a servir de referencial para a construção do PDI, pretendendo, com isso, responder dúvidas e questionamentos vários das IES quanto a sua concepção, forma e conteúdo, desde que foi introduzido como requisito obrigatório para o protocolo de processos de autorização de cursos e de credenciamento de IES. Na realidade, este documento vem sacramentar o enfoque "credencialista" conferido ao PDI na Resolução 10/2002 (CONSELHO NACIONAL DE EDUCAÇÃO, 2002). Tendo em vista a natureza normativa do documento, ele é uma boa fonte para avaliar o papel que o MEC espera que o PDI desempenhe dentro e fora da instituição universitária. Em primeiro lugar, é assim definido:

O Plano de Desenvolvimento Institucional - PDI, elaborado para um período de cinco anos, é o documento que identifica a Instituição de Ensino Superior (IES), no que diz respeito à sua filosofia de trabalho, à missão a que se propõe, às diretrizes pedagógicas que orientam suas ações, à sua estrutura organizacional e às atividades acadêmicas que desenvolve e/ou que pretende desenvolver. (BRASIL, 2002, p. 2). 
Esse tópico talvez suscite a idéia de que o objetivo do PDI é permitir que a instituição possa expressar livremente sua proposta de trabalho. No entanto, analisando um dos pressupostos básicos a ele atribuídos, nesse documento, as contradições começam a aparecer, desde a contraposição criatividade/liberdade $x$ eixos temáticos obrigatórios, como se segue:

A construção do PDI poderá se fazer de forma livre, para que a Instituição exercite sua criatividade e liberdade [!], no processo de sua elaboração. Entretanto, os eixos temáticos constantes das instruções a seguir, deverão estar presentes[!], pois serão tomados como referenciais das análises subseqüentes, que se realizarão por comissão designada pela SESU/MEC para este fim. (BRASIL, 2002, p. 2).

Ainda no segundo semestre de 2002, em fins da gestão do Ministro da Educação do governo anterior, aumentou a pressão no sentido de estabelecer uma obrigatoriedade geral de recredenciamento das universidades e centros universitários que culminou na Resolução CNE/CES 23, de 5 de novembro de 2002. No artigo $2^{\circ}$ está claramente ratificada a centralidade e abrangência conferida ao PDI como instrumento de planejamento e avaliação:

o recredenciamento de universidades

e centros universitários deverá ser centrado na avaliação do Plano de Desenvolvimento Institucional - PDI de cada instituição e nos critérios vigentes da avaliação institucional, promovendo-se equilíbrio entre critérios objetivos e subjetivos de avaliação de qualidade, de modo a contemplar agilidade no processo, progressivida- de nas metas fixadas e eficácia e eficiência nas análises construtivas dos desempenhos institucionais, ao longo de tempos determinados.

Além da centralidade e abrangência, pode-se perceber, claramente, o atrelamento a "critérios vigentes de avaliação institucional". Esses critérios estão expressos nos Manuais de Avaliação Institucional, anexados ao Parecer 267/2002, que tratou da questão do credenciamento de universidades e de centros universitários.

A experiência realizada na universidade ${ }^{\natural}$, que nos servirá de exemplo ilustrativo, foi desenvolvida de agosto a novembro de 2002, baseada, portanto, na legislação promulgada até março de 2002 e na orientação publicada, em junho, pelo MEC/SESu. $O$ que importa registrar, agora, é que o fato da construção do PDI ter-se orientado por um levantamento da legislação vigente não significou uma aceitação acrítica desta proposta, muito pelo contrário. A percepção do desvio de rota do PDI, ao ser transformado em guarda-chuva de um pacote de credenciamento, serviu como um alerta para alguns princípios que deveriam ser presenvados para manter o PDI como real possibilidade de construção de um referente para avaliação institucional, nos moldes de uma avaliação formativa.

\section{A Proposta de Construção do PDI}

Num primeiro momento, como parte do processo de elaboração da proposta de trabalho fezse necessário analisar a trajetória da universidade, seja em termos de experiências já realizadas, de planejamento institucional (SEGENREICH, 2002a) ou da proposta legal do PDI, sinte-

${ }^{1}$ A universidade em questão não será identificada, basta ter como referência que se trata de uma instituição consolidada, de médio porte e de natureza comunitária.

Ensaio: aval. pol. públ. Educ., Rio de Janeiro, v.13, n.47, p. 149-168, abr.jun. 2005 
tizada no item anterior, tendo em vista que a definição de planos estratégicos em nível institucional, como vem sendo exigido pelo MEC, através de legislação específica, não é uma sistemática totalmente nova para muitas universidades.

\section{Antecedentes}

No caso da universidade em questão, experiências de planejamento foram desenvolvidas desde o final da década de 60, por iniciativa própria, quando da implantação da Reforma Universitária. Apesar de não restar documentação mais expressiva das primeiras experiências, o importante é o registro de uma sistemática que adota o princípio de um Plano Diretor Institucional, em termos de diretrizes de ação. $\bigcirc$ primeiro Plano Diretor da Universidade foi consolidado e publicado na década de 80, do século passado, procurando orientar suas atividades por um decênio em termos de diretrizes, prioridades e metas qualitativas a serem intemalizadas pela Universidade.

No início da década de 90, entre 1993 e 1995, foi desenvolvido novo processo de planejamento institucional, com o objetivo de definir um Planejamento Estratégico para a Universidade mas que não chegou a ser finalizado, inclusive, pelo nível excessivo de detalhamento de dados demandados às unidades organizacionais. Dirigentes da época comentaram que planejar detalhadamente para um horizonte a longo prazo, distante no tempo, se aproximava mais da "ficção científica" do que do planejamento estratégico. Esta advertência foi levada em consideração no Projeto 2003 - 2007.

Em 1995, o novo Reitor retoma a trajetória do Planejamento Estratégico apresentando o Projeto de Plano Diretor 1995/2004 para discussão, no qual estão definidas a missão, objetivos e diretrizes gerais da instituição e, também, diretrizes por área de atuação. Foi este um dos principais documentos utilizados como ponto de partida para o PDI 2003 - 2007. Outros documentos fundamentais senviram, também, de base para a definição da natureza e missão da Universidade, destacandose: o Estatuto e o Regimento; o "Marco Referencial", documento aprovado pelo Conselho Universitário, que contém os princípios norteadores da instituição, em termos dos objetivos a serem atingidos e dos compromissos que devem ser assumidos pelos que fazem parte da universidade; e, não menos importante, o Projeto Político-Pedagógico da Universidade, aprovado pelo Conselho Universitário, no momento em que se elaborava a proposta de organização do PDI.

Além do Plano Diretor Decenal, a universidade tem operado, na perspectiva de planejamento a curto e médio prazo, com: (a) Planos ou projetos de ação pelo período de um ano, compatíveis com seu dimensionamento acadêmico e com a proposta orçamentária; (b) Planos diretores de dois anos, por solicitação da Vice-Reitoria Acadêmica, no momento em que um novo Diretor de Departamento, eleito a cada dois anos, assume o cargo; e, (c) Projetos especiais sob demanda.

Foi possível inferir, nesta análise dos antecedentes, que a universidade em questão tinha uma cultura de planejamento por parte da direção mas apenas recentemente desenvolvia uma sistemática de acompanhamento e avaliação². Por um lado, essa cultura de planejamento ainda não havia penetrado na capilaridade do tecido institucional como um todo e, muito menos, a sistemática de acompanhamento e avaliação como instrumento de desenvolvimento institucional. Tal percepção foi levada em consideração ao se definir objetivos e pressupostos da proposta de construção do PDI.

\footnotetext{
${ }^{2}$ A Universidade participou do PAIUB elaborando projeto e desenvolvendo algumas sistemáticas de acompanhamento e avaliação, que foram incorporadas institucionalmente.
} 


\section{Objetivos e Pressupostos da Proposta de Desenvolvimento do PDI}

O Plano de Desenvolvimento Institucional requerido pela instituição (SEGENREICH, 2002a) teve por objetivo não apenas atender ao Sistema de Ensino Superior como, também, aperfeiçoar seu próprio modelo de Plano Diretor/Plano Estratégico, através da adoção de uma metodologia participativa de elaboração, como também da implantação de um processo sistemático de acompanhamento e avaliação.

Os pressupostos foram assim definidos na proposta de trabalho:

- Um objetivo específico/proposta ou linha de ação: (a) é uma antecipação, seu conteúdo não tem a ver com acontecimentos ou objetos pertencentes ao ambiente passado do ator que o elabora, porém com acontecimentos ainda não verificados, mas que se encontram indicados em objetivos gerais de uma instituição ou grupo; (b) tem efeito operatório, ou seja, é uma antecipação que se deseja realizar pessoalmente; o objetivo específico ou projeto constitui o modo mais próximo da realização de uma ação; no caso de uma ação coletiva, implicando a intervenção de múltiplos atores, é o projeto ou objetivo específico que fornece a representação comum que permite a realização coordenada das operações de execução; (c) tem efeito mobilizador da atividade dos atores implicados - por um lado é importante que o objetivo específico ou projeto encontre sua origem na motivação das pessoas, todavia nem o impulso nem o desejo, por si sós, realizam um projeto; importa saber contextualizá-lo no âmbito institucional.
- O sistema de planejamento é: (a) um processo cíclico de identificação de objetivos gerais e específicos, desenvolvimento de linhas e projetos de ação, avaliação desses projetos e identificação de novos objetivos específicos para reiniciar o ciclo; e, (b) um processo composto de imagens antecipadoras e retrospectivas.

- A participação dos atores implica: (a) intervenção de todos os atores que atuam no campo da ação principal porque o objetivo específico/projeto supõe a visão da relação 'finalidade-objetivo-fim', fundado na relação 'desejo-limites-valor' mediatizado pela relação 'recursos-limitações-gestão'; e, (b) um processo de negociação ${ }^{3}$ entre pares de atores, entre complementares [relação horizontal] e entre atores em diferentes instâncias [relação vertical]. (SEGENREICH, 2002 a, p.6/7)

\section{Foco Principal do Projeto}

Procurando compatibilizar a experiência da universidade, o roteiro proposto pelo MEC e a concepção do que deve ser um plano de desenvolvimento institucional, optou-se por desenvolver um processo de definição de objetivos e linhas de ação da universidade, com a participação de toda a comunidade universitária. Paralelamente a esse processo, foram levantados dados sobre a instituição, de acordo com os eixos definidos pelo MEC e por uma avaliação das especificidades da Universidade. Chegou-se a uma primeira versão do PDI em dezembro de 2002, deixando seus possíveis desdobramentos - desenvolvimento dos Projetos de Ação para o ano de 2003 e Avaliação do Sistema como um todo - para uma definição posterior.

Com a introdução do Plano de Desenvolvimento Institucional, pelo prazo inicial de $5 \operatorname{anos}^{4}$, a sistemática de planejamento

\footnotetext{
${ }^{3}$ Negociação é a palavra-chave para a avaliação de quarta geração, de acordo com Penna Firme (1994).

${ }^{4}$ A partir da Resolução 23 de 5/1 1/2002, no final do processo de construção do PDI, esse prazo foi estendido para dez anos.
} 
da universidade ficaria instituída em vários níveis e âmbitos: Plano Diretor, Plano de Desenvolvimento Institucional, Plano de Desenvolvimento do Departamento (mandato do diretor eleito), planos e projetos por uni- dades e projetos especiais.

No quadro, a seguir, é possível visualizar como ficou a proposta de estrutura da $1^{a}$ Versão do PDI da universidade, comparada ao roteiro do $\mathrm{MEC}$.

Quadro 1: Estrutura do PDI da Universidade comparado ao do MEC

\begin{tabular}{|c|c|}
\hline ROTEIRO DA UNIVERSIDADE & ROTEIRO DO MEC \\
\hline \multicolumn{2}{|l|}{$\begin{array}{l}\text { Introdução: antecedentes do PDI e } \\
\text { estrutura do documento }\end{array}$} \\
\hline 1. Perfil institucional & 1. Perfil Institucional \\
\hline 1.1 Histórico & $\begin{array}{l}\text { 1.1 Missão(histórico, áreas de atuação, } \\
\text { inserção regional, diretrizes pedagógicas) }\end{array}$ \\
\hline 1.2 Missão (finalidades) & Missão (finalidades) \\
\hline 1.3 Objetivos institucionais gerais & 1.2 Objetivos gerais da instituição \\
\hline \multicolumn{2}{|l|}{ 1.4 Diretrizes pedagógicas } \\
\hline $\begin{array}{l}1.5 \text { Objetivos institucionais específicos 2003-2007 } \\
\text { (qualificadas para o período como um todo) }\end{array}$ & $\begin{array}{l}\text { 1.3 Metas para atingir objetivos gerais } \\
\text { (quantificadas e por prazos) }\end{array}$ \\
\hline 2. Plano de Desenvolvimento 2003-2007 & 2. Planejamento e Gestão Institucional \\
\hline 2.1 Organização do Plano & 2.1 Objetivos e metas \\
\hline \multicolumn{2}{|l|}{$\begin{array}{l}\text { 2.2 Linhas de ação por órgão } \\
\text { (qualificadas/quantificadas e por prazos) }\end{array}$} \\
\hline 3. Organização acadêmica e administrativa & 2.2 Organização acadêmica e administrativa \\
\hline \multicolumn{2}{|l|}{ 3.1. Organização geral da universidade } \\
\hline \multicolumn{2}{|l|}{ 3.2 Órgãos executivos } \\
\hline \multicolumn{2}{|l|}{ 3.3. Órgãos colegiados e comissões } \\
\hline \multicolumn{2}{|l|}{ 3.4. Relações externas } \\
\hline \multicolumn{2}{|l|}{ 3.5. A Comunidade Universitária } \\
\hline $\begin{array}{l}\text { 4. Atividades desenvolvidas: } \\
\text { ensino, pesquisa, extensão }\end{array}$ & $\begin{array}{l}\text { 2.3 Planejamento e Organização } \\
\text { Didático-pedagógicos }\end{array}$ \\
\hline \multicolumn{2}{|l|}{$\begin{array}{l}\text { 4.1. Planejamento e organização } \\
\text { didático-pedagógicos }\end{array}$} \\
\hline 4.2. Oferta de Cursos e Programas & 2.4 Oferta de cursos e programas \\
\hline 5. Infra-estrutura Física e Acadêmica & 2.5 Infra-estrutura Física e Acadêmica \\
\hline 6. Aspectos Financeiros e Orçamentários & 2.6 Aspectos Financeiros e Orçamentários \\
\hline $\begin{array}{l}\text { 7. Avaliação e Acompanhamento do } \\
\text { Desempenho Institucional }\end{array}$ & $\begin{array}{l}\text { 3. Avaliação e Acompanhamento do } \\
\text { Desempenho Institucional }\end{array}$ \\
\hline
\end{tabular}

Fonte: Segenreich (2001a). 
No roteiro do documento, procurou-se estabelecer como itens independentes o que se considerava como sendo o PDI propriamente dito - itens 1 e 2 - de seu restante que se caracteriza mais como documento de um processo de credenciamento. No próximo item, será apresentado o processo de levantamento e análise desses dois itens, principalmente no que concerne à definição de objetivos específicos institucionais (item 1.5) e linhas de ação por órgão (item 2.2), juntamente com os documentos básicos já disponíveis.

\section{Definição de Objetivos e Especificação das Linhas de Ação: Preparativos do Trabalho de Campo}

O levantamento de objetivos específicos e linhas de ação da instituição teve que ser precedido por uma série de decisões prévias, tais como: definição das unidades de informação; explicitação e ratificação dos objetivos institucionais gerais; redefinição dos objetivos específicos/áreas de atuação; elaboração dos instrumentos de coleta de dados.

\section{Identificação das unidades de informação}

Foram definidas 76 unidades de informação em todas as áreas e instâncias da
Universidade, mediante mapeamento exaustivo da sua estrutura organizacional e consulta aos dirigentes. Houve certa dificuldade inicial na inclusão, lado a lado, de setores tão diversos como a Reitoria, o Departamento de Física , o Serviço Médico da Universidade e a Associação de Funcionários, no entanto, rapidamente a direção da instituição acolheu a idéia.

É imprescindível que os dirigentes da instituição acompanhem de perto esta definição para que reconheçam a legitimidade da definição das unidades de informação e não sejam introduzidas distorções no processo. No caso da universidade em foco, por exemplo, as coordenações de graduação e pósgraduação ficaram inseridas no departamento acadêmico em que estão sediadas. Foram consideradas como unidades de informação somente as coordenações centrais de graduação e pós-graduação.

\section{Explicitação/ratificação dos objetivos institucionais gerais}

Tendo em vista que o Projeto Pedagógico (PPI) havia sido aprovado no momento de preparação do trabalho de campo, foi possível assumir diretamente os objetivos institucionais gerais estatutários, nele ratificados. A título de ilustração, dois deles estão transcritos, no Quadro 2, a seguir.

Quadro 2: Objetivos institucionais gerais

1. (...)

2. $O$ desenvolvimento do ensino e o aprofundamento da investigação e da pesquisa, para criar e difundir uma visão do universo e do ser humano consciente da necessária unidade que deve reger a multiplicação do saber.

3. (..) e 4. (...)

4. O intercâmbio e a cooperação com instituições educacionais, científicas e culturais, nacionais e estrangeiras, no intuito de emprestar universalidade ao sentido de sua missão.

Fonte: Projeto Pedagógico Institucional. 
Mapeamento dos objetivos institucionais/áreas de atuação apresentados pelas unidades que participaram do Planejamento Estratégico desenvolvido de 1993 a 1995

Considerou-se importante levantar os objetivos/linhas de ação definidas pelas unidades que participaram deste processo de planejamento e que preencheram os formulários com o objetivo de demonstrar que mesmo aquele processo incompleto poderia servir de base ao momento atual. Abre-se a possibilidade, para estas unidades, de avaliar as propostas feitas oito anos atrás com base nas realizações alcançadas com sucesso, além da possibilidade de redefinir metas, no caso de propostas não concretizadas.

\section{Redefinição dos objetivos institucionais/áreas de atuação}

A redefinição dos objetivos institucionais específicos por áreas de atuação se fez mediante a atualização dos objetivos do Plano Diretor 1995 - 2004, a fim de servirem de base inicial para o trabalho das unidades. Foram definidos junto aos principais dirigentes da instituição: inicialmente os vice-reitores e, finalmente, o reitor, com vistas a sua consolidação e aprovação final.

Ficaram explicitados 40 objetivos institucionais específicos, que serviram de balizamento à definição dos objetivos específicos das unidades, de acordo com as seguintes áreas: ensino de graduação; ensino de pósgraduação stricto sensu e lato sensu; educação a distância; pesquisa (produção e divulgação); extensão; gestão; ação comunitária; e, relação com a comunidade.

Como exemplo ilustrativo transcrevemos, a seguir, alguns exemplos de objetivos específicos por linhas de ação, nas áreas de graduação e pós-graduação.

Quadro 3: Objetivos Institucionais Específicos por Área (PDI 2003 - 2007)

\section{Área 1 - Graduação: (6 linhas)}

1. (...)

2. Implementar um processo de revisão curricular visando à flexibilização do currículo e à definição das atividades complementares.

3. (...)

4. Fortalecer os procedimentos contínuos de avaliação de todos os cursos oferecidos na Universidade, visando ao estabelecimento de uma política acadêmica voltada para a qualidade.

5. (...)

6. Apoiar iniciativas de iniciação científica na Universidade que valorizem o processo de formação para a pesquisa.

\section{Área 2 - Pós-Graduação "stricto sensu" e "lato sensu": ( 4 linhas)}

7. Completar o processo de implantação da pós-graduação stricto sensu nas áreas em que o lato sensu já está desenvolvido.

8. (...) e 9. (...)

10. Ampliar a oferta de cursos de especialização de modo a utilizar a capacidade docente nas diversas unidades, de acordo com seu interesse acadêmico e atender às demandas da sociedade.

Fonte: Segenreich (2002b). 


\section{Elaboração de instrumento de coleta de dados}

O instrumento de coleta de dados foi elaborado com o cuidado de levantar contribuições viáveis aos olhos dos participantes do projeto, visando evitar o problema de falta de retorno ocorrido na experiência anterior de Planejamento Estratégico, composto de três partes. Na primeira, procurava-se ter uma visão esquemática das áreas de atuação de cada unidade de informação e de uma avaliação de sua situação no momento, em termos de pontos fortes e pontos fracos. Sempre que se julgava necessário, havia uma breve explicação do que se pretendia com aquele item, como se fez, por exemplo com a identificação dos referidos pontos:

Pontos Fortes: indicar, por itens, realizações anteriores que caminham na direção dos objetivos gerais e que, principalmente, já cobrem os objetivos institucionais específicos previstos para o PDI 2003-2007.
Exemplos: curso de mestrado $X$ com avaliação alta na CAPES, participação de todo o corpo docente nos cursos de graduação e pós-graduação, desenvolvimento de pesquisas interdisciplinares com departamento $Y$ etc.

Pontos Fracos: indicar, por itens, aspectos do funcionamento da unidade que precisam ser aperfeiçoados para atingir os objetivos gerais da instituição e, mais especificamente, os objetivos previstos para o PDI 2003-2007 ou, ainda, algum outro objetivo não explicitado no documento de apoio.

Exemplos: necessidade de implantar o doutorado na área de...; falta de instalações físicas adequadas para laboratórios de... para....; isolamento em relação a unidades da Universidade tais como... para....; etc.

Na segunda parte do instrumento solicitava-se a definição de linhas de ação por área de atuação, havendo um formulário destinado a cada linha de ação. $\bigcirc$ modelo dessa parte do formulário está no Quadro 4.

Quadro 4: Formulário de Definição das Linhas de Ação por Área

\begin{tabular}{|c|c|c|c|c|c|c|c|}
\hline \multicolumn{8}{|c|}{ Proposta 1 (enunciar proposta com subtítulos) } \\
\hline \multicolumn{8}{|c|}{ Justificativa (breve, frente à situação da unidade e/ou objetivos institucionais) } \\
\hline \multicolumn{5}{|c|}{ Vigência } & \multicolumn{3}{|c|}{$\begin{array}{l}\text { Objetivo a que está vinculado } \\
\text { (identificar com número) }\end{array}$} \\
\hline 2003 & 2004 & 2005 & 2006 & 2007 & Geral & $\overline{\mathrm{PDI}}$ & Outro \\
\hline \multicolumn{8}{|c|}{$\begin{array}{l}\text { Outro objetivo institucional a que está vinculado: (caso não se enquadre no } \\
\text { objetivos gerais ou específicos do PDI) }\end{array}$} \\
\hline \multicolumn{5}{|c|}{ Recursos envolvidos } & \multicolumn{3}{|c|}{ Dimensionamento acadêmico } \\
\hline Próprios & \begin{tabular}{l|} 
Verba \\
Univ.
\end{tabular} & \begin{tabular}{l|} 
Verbas \\
Externas
\end{tabular} & \multicolumn{2}{|c|}{$\begin{array}{l}\text { Não envolve } \\
\text { recursos }\end{array}$} & Altera & \multicolumn{2}{|c|}{ Não altera } \\
\hline & & & & & & & \\
\hline
\end{tabular}

Fonte: Segenreich (2002c). 
Em relação a cada item foram incluídas as seguintes instruções:

Linhas de Ação: referem-se às iniciativas (realizáveis) que indicam como cada unidade de informação vai procurar atingir os objetivos institucionais gerais e, principalmente, os específicos para o período 2003-2007, a partir dos pontos fracos e dos fortes detectados na análise da situação da unidade, nas diferentes áreas de atuação da Universidade. Para cada linha de ação preencher um quadro do formulário. Dependendo da natureza da unidade, sua ação pode abranger um número maior ou menor de áreas de atuação e objetivos específicos.

Exemplos: implantar doutorado na área de (...); criar curso de especialização em (...); desenvolver projeto de extensão na área de (...) em convênio com (...); ampliar oferta de vagas no curso de (...); desenvolver programa interdepartamental de (....) com o departamento de (....). Consultar, também, exemplos concretos no material de apoio: os objetivos estratégicos específicos do setor a que está ligado, as ações, medidas ou metas indicadas pelas diversas unidades de informação.

Área de atuação em que está inserida indicar a área de atuação em que considera que a linha de ação ficaria melhor inserida. Caso considere que sua linha de ação se insere em mais de uma linha de ação indiqueas priorizando a mais pertinente. Caso considere que sua linha de ação não se insere em nenhuma das oito linhas de atuação relacionadas no material de apoio, indique a nova área de atuação que proporia para incluí-la.

Objetivo institucional a que está vinculada - este item segue o mesmo raciocínio da linha de atuação, tanto no caso de se vincular a mais de um objetivo como no caso de não se vincular a nenhum dos 40 objetivos institucionais específicos já explicitados.
Tipo de objetivo a que está vinculada situar a linha de ação proposta em relação aos objetivos existentes - gerais e PDI - sinalizando para o caso em que foi explicitado um novo objetivo -outro. Basta assinalar com um X a(s) opção(ões) pertinente (s).

Vigência - tem por objetivo situar a duração e localização da linha de ação no período de vigência do PDI. Basta assinalar com um $X$ os anos em que pretende desenvolver a linha de ação indicada. Esse tipo de informação dará uma boa idéia à unidade de origem, do volume e seqüência de trabalho que pretende desenvolver, assim como, às demais unidades, das atividades que estão sendo desenvolvidas em paralelo, para melhor integração.

Recursos envolvidos - tem por objetivo apresentar uma primeira posição estratégica sobre os recursos envolvidos. Basta assinalar com um $X$ a opção mais adequada, o detalhamento será feito quando da elaboração do projeto de ação.

Dimensionamento acadêmico - tem o mesmo objetivo do item anterior, em relação a possíveis alterações no dimensionamento acadêmico. Basta assinalar com um X a opção mais adequada, o detalhamento será feito quando da elaboração do projeto de ação.

É possível perceber nas entrelinhas destas instruções a proposta de dar flexibilidade de resposta e possibilidade de novas alternativas, mesmo em um quadro de preenchimento aparentemente fechado.

Finalmente na terceira parte do instrumento, os participantes foram convidados a complementar suas informações, nos seguintes termos: 
Incluir observações/críticas/sugestões que julgar pertinentes acerca dos objetivos institucionais apresentados, do que espera de outras unidades, do processo de elaboração do PDI, do Seminário programado [...] enfim, sobre qualquer aspecto que não tenha encontrado espaço para explicitar na parte mais padronizada do formulário. Essas observações serão analisadas para discussão, no que couber, no Seminário previsto para novembro de 2002. (SEGENREICH, 2002c)

Esta parte do formulário tinha por objetivo dar espaço para as unidades de informação poderem se expressar com mais liberdade sobre o próprio conteúdo e processo de elaboração do PDI. Além da contribuição específica de sua unidade como elemento ativo da estrutura da Universidade, considerava-se importante que cada unidade fosse levada a pensar e opinar sobre os objetivos institucionais propostos, assim como linhas de ação que esperavam ser desenvolvidas também por outras unidades da instituição. Na maioria das vezes, as linhas de ação não se desenvolvem isoladamente e, neste sentido, é preciso definir conexões e interdependências.

\section{Desenvolvimento do PDI Propriamente Dito: Levantamento de objetivos específicos e linhas de ação}

Foi realizado através das seguintes etapas desenvolvidas, basicamente, entre setembro e novembro de 2002: propostas de ação às unidades; acompanhamento do trabalho das unidades, recebimento e consolidação dos dados; compatibilização e devolução das propostas às unidades; levantamento dos dados institucionais solicitados pelo MEC.

\section{Propostas de ação para as unidades}

Foram apresentadas nas reuniões dos órgãos colegiados de nível intermediário e reuniões específicas nas Vice-Reitorias. A opção pelo órgão colegiado, no caso das unidades acadêmicos, se deve à necessidade de garantir, durante o processo, a participação de todos os segmentos da comunidade universitária - dirigentes, professores, alunos, funcionários.

Foi entregue, pessoalmente, a todos os responsáveis pelas unidades de informação, o formulário padronizado para preenchimento das propostas de ação por área de atividade, juntamente com o seguinte material de apoio: (a) objetivos gerais institucionais; (b) objetivos específicos institucionais para o período do PDI; (c) mapeamento das linhas de atuação propostas por todas as unidades que participaram do Plano Estratégico 1993-95.

\section{Acompanhamento do trabalho das unidades, recebimento e consolidação dos dados}

O levantamento desses dados se prolongou até a primeira semana de dezembro de 2002, obtendo $97 \%$ de respostas das unidades de informação. Faltaram somente os dados dos diretórios estudantis. Apesar dos representantes estudantis haverem comparecido à reunião realizada na Vice-Reitoria Comunitária em setembro, as eleições ocorridas durante o mês de outubro prejudicaram o envio de suas respostas e o novo grupo que assumiu não se sentiu em condições de dar essa contribuição. 


\section{Compatibilização e devolução das propostas das unidades}

Recebidas as propostas, elas foram organizadas agrupadas para discussão nos diferentes âmbitos: departamentos, diretorias, centros, vice-reitorias. Estava prevista, também, a realização de um seminário para consolidar e/ou reformular os objetivos institucionais, todavia, como não se efetivou, foi elaborado um documento, descrito no próximo item, que desse um retorno a toda a instituição do que o conjunto de unidades de informação havia realizado até o momento.

\section{Levantamento dos dados institucionais solicitados pelo MEC}

Estes dados foram levantados no decorrer de todo o processo obedecendo a alguns critérios básicos:

- Sempre que havia um documento institucional publicado, era indicado como fonte, fazendo-se um breve resumo do seu conteúdo. Foi o caso do Estatuto/Regimento, Catálogo dos Cursos de Graduação, Catálogo dos Cursos de Pós-Graduação, Balanço Social, Manual do Aluno de Graduação, Projeto Político Pedagógico Institucional e Manual do Professor.

- Os dados foram solicitados ou ao órgão que centraliza a função de planejamento e avaliação da Universidade, ou aos órgãos que coordenam o assunto pesquisado.

- Procurou-se aproveitar os dados existentes na Universidade, montando-se novos quadros e tabelas, na medida do necessário, para que se pudesse avaliar, no documento construído, a suficiência e pertinência desses dados.

No final de novembro, a coleta de dados foi encerrada para fechamento da $1^{a}$ versão do PDI.

\section{Consolidação da

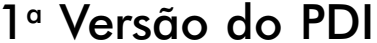

A $1^{a}$ Versão do PDI, incluindo a definição de objetivos e linhas de ação propostas pelas unidades (ainda sujeita a discussão), bem como os dados institucionais solicitados pelo MEC sobre o potencial institucional da Universidade para realizar os objetivos propostos, foi finalizada na primeira quinzena de dezembro.

Apesar do PDI ser o produto principal desse trabalho, o projeto gerou um conjunto de relatórios que o complementam entre os quais destacamos o Relatório com a análise dos objetivos e linhas de ação e - Relatório Técnico Final, entregue à direção da instituição.

\section{Relatório contendo subsídios para uma reavaliação}

A devolução às unidades de informação se efetivou por meio do relatório Subsídios para uma reavaliação (SEGENREICH, 2002 b), elaborado com o objetivo de auxiliar unidades ou conjunto de unidades que quisessem trabalhar, independentemente. Nele é feita uma primeira análise das propostas encaminhadas. Paralelamente foi encaminhada uma visão geral de todas as 511 linhas de ação enunciadas pelas 76 unidades de informação da Universidade.

Vários quadros de acompanhamento foram organizados. Entre eles apresentamos, a título de ilustração, um quadro que permite uma visão quantitativa das linhas de ação propostas por uma pequena amostra de unidades de informação. 
Quadro 5: Linhas de Ação por Área de Atuação e Unidade de Informação

\begin{tabular}{|l|l|l|l|l|l|l|l|l|l|l|l|}
\hline \multirow{2}{*}{$\begin{array}{l}\text { UNIDADE } \\
\text { INF }\end{array}$} & \multirow{2}{*}{ No } & \multicolumn{7}{|c|}{ ÁREAS DE ATUAÇÃO PROPOSTAS EM SETEMBRO DE 2002 } \\
\cline { 3 - 13 } & GRA & PGR & EAD & PES & EXT & GES & COM & SOC & OUT & $\begin{array}{l}\text { TOT } \\
\text { INDIC }\end{array}$ \\
\hline DAR & 03 & 3 & ---- & ---- & ---- & ---- & 1 & --- & --- & ---- & 04 \\
\hline SRH & 10 & ---- & ---- & ---- & ---- & ---- & 10 & ---- & ---- & ---- & 10 \\
\hline EDU & 17 & 6 & 10 & 4 & 2 & 5 & ---- & ---- & 5 & ---- & 32 \\
\hline PSI & 06 & 4 & 3 & ---- & 1 & ---- & ---- & ---- & ---- & ---- & 08 \\
\hline DIR & 06 & 4 & 2 & ---- & 2 & 1 & 1 & 1 & 1 & ---- & 12 \\
\hline NPJ & 03 & 3 & ---- & ---- & ---- & ---- & ---- & ---- & ---- & ---- & 03 \\
\hline SER & 11 & 6 & 5 & ---- & 3 & 1 & 2 & ---- & 1 & ---- & 18 \\
\hline SOC & 07 & 3 & 3 & ---- & 2 & 1 & ---- & ---- & 1 & ---- & 10 \\
\hline FIS & 05 & 5 & 2 & 1 & 3 & 3 & ---- & ---- & 2 & ---- & 16 \\
\hline INF & 03 & 2 & 2 & ---- & 2 & 2 & ---- & ---- & ---- & ---- & 08 \\
\hline
\end{tabular}

Fonte: Segenreich (2002b)

GRA - graduação

PGR - pós-graduação

EAD - educação a distância

PES - pesquisa

EXT - extensão e responsabilidade social

Seu objetivo é oferecer uma primeira idéia das linhas prioritárias de atuação da unidade e levantar questões para discussão. No caso do setor de Recursos Humanos (SRH), por exemplo, é bem compreensível seu foco centrado na área de gestão mas é de estranhar sua ausência na área referente à ação comunitária e a da relação com a sociedade, por exemplo. Comparando as unidades acadêmicas da Educação (EDU) e do Direito $(\mathrm{DIR})$, pode-se perceber a ênfase maior de atuação da Educação na área de pós-graduação. No caso de Direito, sua análise em conjunto com - Núcleo de Prática Jurídica (NPJ) mostra esta área de formação mais voltada para a atuação na área de graduação. A Diretoria de Admissão e Registro (DAR), por outro lado, concentra seus esforços na área de graduação e gestão, mas nada propõe para a pós-graduação apesar de ser sua área de competência também.

GES - gestão

COM - ação comunitária

SOC - relação com a sociedade

OUT - outras

Algumas observações sobre esse quadro foram registradas no relatório analítico encaminhado às unidades de informação (SEGENREICH, 2002b) para funcionarem como elemento disparador para análises a serem feitas pelas próprias unidades, individualmente ou em conjunto.

\section{Relatório Técnico}

Neste Relatório é feita uma análise preliminar do processo de construção do PDI alertando-se, mais uma vez, para a necessidade de que todos participem desse processo de análise, assim como participaram de sua construção. Cabe destacar os seguintes pontos que podem ser úteis a qualquer instituição que esteja desenvolvendo esse processo:

- Falta uma definição mais ampla das unidades de informação. Os dados foram levan- 
tados em diferentes fontes e, dependendo da fonte - catálogo acadêmico ou balanço social, por exemplo - a unidade muda quase inteiramente sua configuração. Ë preciso que cada unidade, inclusive o departamento, tenha uma definição mais institucional que situe, inclusive, o ano de sua criação. Os organogramas precisam ser cuidadosamente verificados quanto à correspondência com a realidade atual.

- A publicação sistemática de documentos informativos, como o Manual do Aluno de Graduação e o Balanço Social, auxilia o PDI na medida em que podem ser transformados em anexos do documento principal. A produção de documentos de avaliação interna como o intitulado "Situação dos Departamentos", elaborado pela Coordenação de Avaliação da Universidade, pode também servir a esse propósito. Essa medida atenderia à seguinte estrutura de anexos proposta pelo próprio MEC (BRASIL, 2002), principalmente no que se refere ao último item: outros documentos relevantes e complementares ao PDI, que a IES entenda que devam fazer parte do mesmo.
- Importa que os dados estatísticos produzidos pela Universidade contenham fonte e data/período a que se referem e que, para o PDI, seja estabelecida a melhor fonte/órgão produtor de informações, assim como, evidentemente, o melhor tipo de informação, a partir do que está incluído em sua primeira versão .

\section{Sistemática de distribuição dos documentos}

Foi acertada com a direção da Universidade, e executada, uma sistemática de produção e distribuição de documentos do PDI, etapa imprescindível nesse tipo de proposta. Alguns relatórios e conjuntos de dados são, em princípio, mais restritos como, por exemplo, a definição dos pontos fracos de cada unidade. Outros, entretanto, foram restringidos, ou pela despesa da distribuição ou pela necessidade de preservar a memória do processo. Todos estão, entretanto, disponíveis na Vice-Reitoria Acadêmica para consulta. Uma visão desses relatórios constitui o Quadro 6 a seguir.

Quadro 6: PDI - Quadro de Distribuição dos Relatórios e Documentos Finais

\begin{tabular}{|c|c|c|c|}
\hline $\begin{array}{l}\text { RELATÓRIOS/DOCUMENTOS } \\
\text { DOCUMENTOS PRINCIPAIS }\end{array}$ & $\begin{array}{l}\text { REITORIA } \\
\text { VRAC }\end{array}$ & $\begin{array}{l}\text { OUTRAS VRs } \\
\text { DIRETORIAS }\end{array}$ & $\begin{array}{l}\text { DEMAIS } \\
\text { UN. DE INF. }\end{array}$ \\
\hline PDI : $1^{0}$ versão & 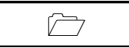 & 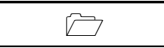 & 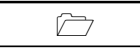 \\
\hline Relatório com análise dos objetivos e linhas de ação & 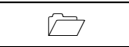 & 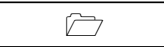 & 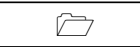 \\
\hline Relatório Técnico & 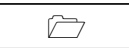 & & \\
\hline \multicolumn{4}{|l|}{ DOCUMENTOS DE APOIO } \\
\hline CD ROM com todos os arquivos do PDI & 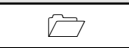 & & \\
\hline Pastas com toda a documentação coletada (VRAc) & 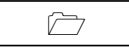 & & \\
\hline $\begin{array}{l}\text { Dados brutos sobre os pontos fracos das } \\
\text { unidades de informação de toda a Universidade }\end{array}$ & $\nabla$ & & \\
\hline Dados brutos das linhas de ação/objetivos do Centro & 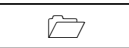 & $\nabla$ & \\
\hline Dados brutos sobre as observações complementares de toda a Universidade & 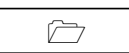 & $\nabla$ & \\
\hline Dados brutos das linhas de ação/ pontos fortes de toda a Universidade & 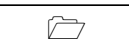 & 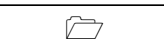 & $\nabla$ \\
\hline
\end{tabular}

Fonte: Segenreich (2002c). 


\section{Considerações Finais: Lições de uma Experiência e Perspectivas}

As "lições aprendidas" nesta experiência de trabalhar efetivamente com um projeto tão desafiador como coordenar a construção do PDI em uma universidade de porte, se apresentam em dois níveis: institucional e de políticas públicas.

Em nível institucional, a experiência concreta de um modelo faz ressaltar a pouca atenção que se atribui à cultura de uma instituição complexa como a universidade. A proposta de um modelo participativo de construção dos objetivos institucionais não se deveu à indicação do MEC, mas da constatação de que o referente de uma instituição somente será assumido se for construído pelos seus atores mediante um modelo de avaliação de quarta geração, isto é, avaliação por negociação contínua. Esta era a proposta do projeto da Universidade ao estabelecer 40 objetivos provisórios e trabalhar com as respostas. $\bigcirc$ processo foi interrompido no momento dessa negociação, mas as unidades ficaram de posse de todo o caminho já percorrido (o que é muito importante) e, em muitos casos, estão prosseguindo o trabalho. Neste início do ano de 2005, esse processo de negociação está sendo retomado pela instituição, no bojo do sistema de avaliação interna instituído pelo SINAES e pode se constituir em uma excelente oportunidade para avaliar a primeira versão do PDI, ratificando ou redefinindo seus objetivos específicos e linhas de ação, como também, até mesmo, seu próprio processo de construção, se for o caso.

Um outro ponto que merece registro é o fato de que o elevado índice de $97 \%$ de respostas se deve não somente ao processo participativo de construção do processo como, também, ao nível de informação solicitado e ao processo de sensibilização desenvolvido. A observação de atores da instituição sobre o "exercício de futurologia", solicitado em experiências anteriores, serviu de balizamento para este projeto, cabendo ser sempre levado em consideração, principalmente agora que o PDI constitui uma das referências centrais do novo processo de avaliação do MEC.

Em nível das políticas públicas fica um alerta para os rumos que estava tomando a proposta do PDI, antes do SINAES. Do bojo de um discurso de avaliação institucional, estava surgindo mais um pacote de controle governamental, instrumento de poder e disciplinação, a partir de indicadores (âmbito do referente) externos à instituição e, freqüentemente, contrários à sua concepção de universidade. Verifica-se, no texto do SINAES, a existência de um conjunto de tópicos considerados como núcleo básico e comum em cada uma das dez dimensões propostas para avaliação. Entretanto, ao lado de cada conjunto de tópicos obrigatórios, é destacado um núcleo de temas optativos que acena com uma abertura para a especificidade de cada instituição que deve ser explorada e até ampliada pelas instituições de educação superior.

Articulando as palavras de Hadii (2001, p. 21) sobre avaliação da aprendizagem com a perspectiva da avaliação institucional pode-se concluir que a avaliação formativa pode trazer subsídios valiosos para o desenvolvimento dessa questão:

colocando-se deliberadamente a serviço do fim que the dá sentido, torna-se um elemento, um momento determinante da ação educativa; propondo-se tanto a contribuir para uma evolução do aluno [da instituição] quanto a dizer o que, atualmente, ele [ela] é; e, inscrevendo-se na continuidade da ação pedagógica [institucional], ao invés de ser simplesmente uma operação externa de controle, cujo agente poderia ser totalmente estrangeiro [estranho] à atividade pedagógica [institucional]. 


\section{Referências}

AFONSO, A. J. Avaliação educacional: regulação e emancipação.São Paulo: Cortez, 2000.

BELLONI, I.; BELLONI, J. A. Questões e propostas para uma avaliação institucional formativa. In: FREITAS, L. C. (Org.). Avaliação de escolas e universidades. Campinas, SP: Komedi, 2003. p. 9-57.

BRASIL. Decreto n 3.860 , de 9 de julho de 2001. Dispõe sobre a organização do ensino superior, a avaliação de cursos e instituições, e dá outras providências. Diário Oficial [da] República Federativa do Brasil, Brasília, DF, 10 de julho de 2001.

. Lei n. 9.394, de 20 de dezembro de 1996. Estabelece as diretrizes e bases da educação nacional. Diário Oficial [da] República Federativa do Brasil, Brasília, DF, 23 de dezembro de 1996.

. Lei n. 10.861, de 14 de abril de 2004. Institui o Sistema Nacional de Avaliação. Diário Oficial [da] República Federativa do Brasil, Brasília, DF, 15 de abril de 2004. n. 72, Seção 1, p. 3-4.

BRASIL. Ministério da Educação. Secretaria de Educação Superior. Plano de Desenvolvimento Institucional - PDI: diretrizes para elaboração. Brasília: MEC/ SESu, jun. 2002.

DIAS SOBRINHO, J. Universidade: Processos de socialização e processos pedagógicos. In: DIAS SOBRINHO, J.; BALZAN, N. C. Avaliação institucional: teoria e experiências. São Paulo: Cortez, 1995, p. 15-36.

COMISSÃO ESPECIAL DE AVALIAÇÃO DA EDUCAÇÃO SUPERIOR (Brasil). Sistema Nacional de Avaliação da Educação Superior SINAES: bases para uma nova proposta da educação superior. Avaliação: revista da Rede de Avaliação Institucional da Educação Superior, Campinas, SP, v. 9, n. 1, p. 9-111, mar. 2004.

CONSELHO NACIONAL DE EDUCAÇÃO (Brasil). Parecer CNE/CES n. 1366, de 12 de dezembro de 2001. Dispõe sobre o recredenciamento, transferência de mantença, estatutos e regimentos de instituições de ensino superior, autorização de cursos de graduação, reconhecimento e renovação de reconhecimento de cursos superiores, normas e critérios para supervisão do ensino superior. Diário Oficial [da] República Federativa do Brasil, Brasília, DF, 20 dez. 2001. Seção 1, p. 49.

. Resolução $n^{\circ}$. 10, de 11 de março de 2002. Dispõe sobre o recredenciamento, transferência de mantença, estatutos e regimentos de instituições de ensino superior, autorização de cursos de graduação, reconhecimento e renovação de reconhecimento 
de cursos superiores, normas e critérios para supervisão do ensino superior do Sistema Federal de Educação Superior. Diário Oficial [da] República Federativa do Brasil, Brasília, DF, 26 mar. 2002. Seção 1, p. 12.

CONSELHO NACIONAL DE EDUCAÇÃO (Brasil). Resolução $n^{\circ}$. 23, de 5 de novembro de 2002. Dispõe sobre o recredenciamento de universidades e centros universitários do sistema federal de educação superior. Diário Oficial [da] República Federativa do Brasil, Brasília, DF, 20 dez. 2002. Seção 1, p. 49.

HADJI, C. A avaliação, regras do jogo: das intenções aos instrumentos. Porto, PT: Porto Editora Ltda, 1994.

A avaliação desmistificada. Porto Alegre: ARTMED, 2001.

INSTITUTO NACIONAL DE ESTUDOS E PESQUISAS EDUCACIONAIS ANÍSIO TEIXEIRA. Roteiro de auto-avaliação institucional 2004. Brasília: MEC, INEP, 2004.

PENNA FIRME, T. Avaliação: tendências e tendenciosidades. Ensaio: avaliação e políticas públicas em educação, Rio de Janeiro, v. 1, n. 2, p.5-12., jan./mar. 1994.

RISTOFF, D. I. Avaliação institucional: pensando princípios. In: DIAS SOBRINHO, J.; BALZAN, N. C. Avaliação institucional: teoria e experiências. São Paulo: Cortez, 1995. p. 15-36.

SGUISSARDI, V. Para avaliar propostas de avaliação do ensino superior. In: Avaliação universitária em questão: reformas do Estado e da educação superior. Campinas, SP: Autores Associados, 1997. p. 41-70.

SEGENREICH, S. C. D. PDI: proposta de plano de trabalho. Rio de Janeiro, 2002a. Documento de trabalho.

. PDI 2003 - 2007: áreas de atuação e objetivos institucionais que contextualizam as linhas de ação: subsídios para uma reavaliação. Rio de Janeiro, 2002b. Documento de trabalho. trabalho.

. PDI 2003 - 2007: relatório técnico. Rio de Janeiro, 2002c. Documento de

Recebido: 07/03/2005

Aceito para publicação em: 09/05/2005 